\title{
Integrated airfoil and blade design method for large wind turbines
}

\author{
Zhu, Wei Jun; Shen, Wen Zhong
}

Published in:

Proceedings of the 2013 International Conference on aerodynamics of Offshore Wind Energy Systems and wakes (ICOWES2013)

Publication date:

2013

Link back to DTU Orbit

Citation (APA):

Zhu, W. J., \& Shen, W. Z. (2013). Integrated airfoil and blade design method for large wind turbines. In W. Shen (Ed.), Proceedings of the 2013 International Conference on aerodynamics of Offshore Wind Energy Systems and wakes (ICOWES2013) Technical University of Denmark.

\section{General rights}

Copyright and moral rights for the publications made accessible in the public portal are retained by the authors and/or other copyright owners and it is a condition of accessing publications that users recognise and abide by the legal requirements associated with these rights.

- Users may download and print one copy of any publication from the public portal for the purpose of private study or research.

- You may not further distribute the material or use it for any profit-making activity or commercial gain

- You may freely distribute the URL identifying the publication in the public portal

If you believe that this document breaches copyright please contact us providing details, and we will remove access to the work immediately and investigate your claim 


\title{
Integrated airfoil and blade design method for large wind turbines
}

\author{
Wei Jun Zhu, Wen Zhong Shen \\ Department of Wind Energy, Technical University of Denmark, \\ DK-2800 Lyngby, Denmark,wjzh@dtu.dk, wzsh@dtu.dk
}

\begin{abstract}
This paper presents an integrated method for designing airfoil families of large wind turbine blades. For a given rotor diameter and tip speed ratio, the optimal airfoils are designed based on the local speed ratios. To achieve high power performance at low cost, the airfoils are designed with an objective of high $C_{p}$ and small chord length. When the airfoils are obtained, the optimum flow angle and rotor solidity are calculated which forms the basic input to the blade design. The new airfoils are designed based on the previous in-house airfoil family which were optimized at a Reynolds number of 3 million. A novel shape perturbation function is introduced to optimize the geometry on the existing airfoils and thus simplify the design procedure. The viscos/inviscid code Xfoil is used as the aerodynamic tool for airfoil optimization where the Reynolds number is set at 16 million with a free-stream Mach number of 0.25 at the blade tip. Results show that these new airfoils achieve high power coefficient in a wide range of angles of attack (AOA) and they are extremely insensitive to surface roughness.
\end{abstract}

\section{Introduction}

The earliest work on airfoil design began at 1900's where laminar airfoils were the main focus. Due to the development of computer technologies during the past century, flat plat theory was no longer popular for airfoil design, instead, numerical tools are mainly used for airfoil optimization. Hicks et al. [1] are one of the earliest aerodynamicists who made the airfoil design by numerical optimization. The design work of wind turbine airfoils were initiated by Tangler and Somers [2,3] resulting in a family of NREL airfoils dedicated for wind turbine blades. More recently, researchers at DTU have made significant contributions in designing the wind turbine airfoils $[4,5,6]$. All these wind turbine airfoils meet the demand of high lift to drag ratio around design lift.

The state of art wind turbine airfoils generally have a high aerodynamic performance which provide the wind turbine blade to operate with high power performance. However, wind turbine blades designed with these airfoils do not necessarily operate in an optimum state because of the separated design of the airfoil and blade. More rigorous wind turbine blade design shall be integrated with specific airfoil design. The goal of maximizing annual energy product (AEP) can be better achieved by coupling an airfoil optimization routine together with the blade element momentum (BEM) theory or other similar tools. The integrated method increases the design complexity and addresses some other issues more than energy capture. The success of the integrated design work requires a sufficiently elaborated optimization tool. This paper provides a starting point for such an integrated design optimisation.

The core of the present optimization work is to develop large wind turbine blade with lower cost of energy (COE). To achieve this goal, new airfoils are designed and employed at specific blade radial positions. At every local blade station, the design objective of each airfoil is high power coefficient and small chord length. Beside this objective, various constrains are imposed, such as roughness insensitivity, maximum lift to drag ratio etc. The objective and constrains are different from each airfoil due to their different local flow condition. In the state of variable speed operation, the flow geometry over the rotor is preserved such that the flow angle is maintained at its optimum position. The blade platform designed in this paper ensures that the blade will have optimum flow geometry such that the axial induction factor approaches $1 / 3$. The optimum flow geometry will not be guaranteed if the blade is constructed with other airfoils because these airfoils are not dedicated to such a blade. Ideally, a perfect rotor can be designed using the integrated method, i.e., construct the blade with airfoils specially designed and use the resulted optimal blade platform.

The paper is organized as following: Section 2 describes the integrated design method; Section 3 presents the airfoil design method and the results; Section 4 shows the platform of the optimum rotor; Conclusions are given in the final section. 


\section{The Integrated Design Method}

The integrated design of airfoil family and blade can be started from the 2D-BEM analysis of an airfoil section at a given blade station. The core of the analysis is the iterative computation of the power coefficient of an airfoil. Because the power performance is an important measure of blade performance, it has often been used as a key reference number during design process [7]. With an aim of decreasing the cost, we introduce the rotor solidity as another parameter together with the power coefficient. In this analysis, we also involve the Prandtl's tip correction to the integrated design where the design of thin airfoils near tip might be affected.

According to the 1D-momentum theory, the solution of the power coefficient is maximized when the axial induction factor is $a=1 / 3$. With this condition being valid, it can be shown that the power coefficient of an airfoil section can be written as:

where the solidity is

$$
C_{p}=\left[(1-a)^{2}+x\left(1+a^{\prime}\right)^{2}\right] x c_{x} \sigma
$$

$$
\sigma=2 F \sin ^{2}(\phi)
$$

and $a, a$ ' are the axial and tangential induced velocity interference factors, respectively, $x$ is the local speed ratio, $c_{x}$ and $c_{y}$ are the tangential and axial force coefficients, respectively, $\sigma$ is the rotor solidity, $\phi$ is the local flow geometry and $F$ is the Prandtl's tip loss function.

It is known that the Prandtl's tip loss function corrects the assumption of solid disk. Thus for rotors with a finite number of blades the correction has to be implemented to the blade design and well as airfoil design. Although various tip loss functions can be used for the design purpose [8], here we use one of the simplest corrections proposed by Prandtl which is written as:

where

$$
F=2 \cos ^{-1}\left(e^{-f}\right) / \pi
$$

$$
f=B(R-r) /(2 r \sin \phi)
$$

In Eq. (1), not all of the variables have been explicitly given except for the axial induction factor that must equal to $1 / 3$. The other parameters can be divided into two groups. Parameters in group 1 contain the values that will not enter into the BEM iterations. Such as the local speed ratio $x$, the length of the blade $R$, the number of the blades $B$ and the airfoil normal and tangential force coefficients. To compute $c_{x}$ and $c_{y}$, the lift and drag coefficients from the airfoils are needed during every step of airfoil optimization, such that

$$
\begin{aligned}
& c_{x}=c_{l}\left(\sin \phi-c_{d} / c_{l} \cos \phi\right) \\
& c_{y}=c_{l}\left(\cos \phi+c_{d} / c_{l} \sin \phi\right) .
\end{aligned}
$$

The other group of the variables will be iteratively solved due to their dependency. These parameters are the power coefficient $C_{p}$, the flow angle $\phi$ and the tangential induction factor $a^{\prime}$. The values of $C_{p}, \phi$ and $a$ ' are initialized with zero before the first BEM iteration.

The geometric parameters in group 1 shall be fixed for a given blade design. In the present study, we take the 5MW reference wind turbine [9] as the reference rotor. This reference wind turbine has a maximum rotational speed of 12.1 RPM and the blade length of $63 \mathrm{~m}$. In this task we are going to design a wind turbine rotor with a rated power about 20MW. Therefore the length of the new blade shall be approximately computed as

$$
R=63 m \sqrt{20 M W / 5 M W}=128 m
$$

According to the reference rotor, in the present work we fix the blade length at $R=130 \mathrm{~m}$ and the tip-speed-ratio (TSR) of 8 . 


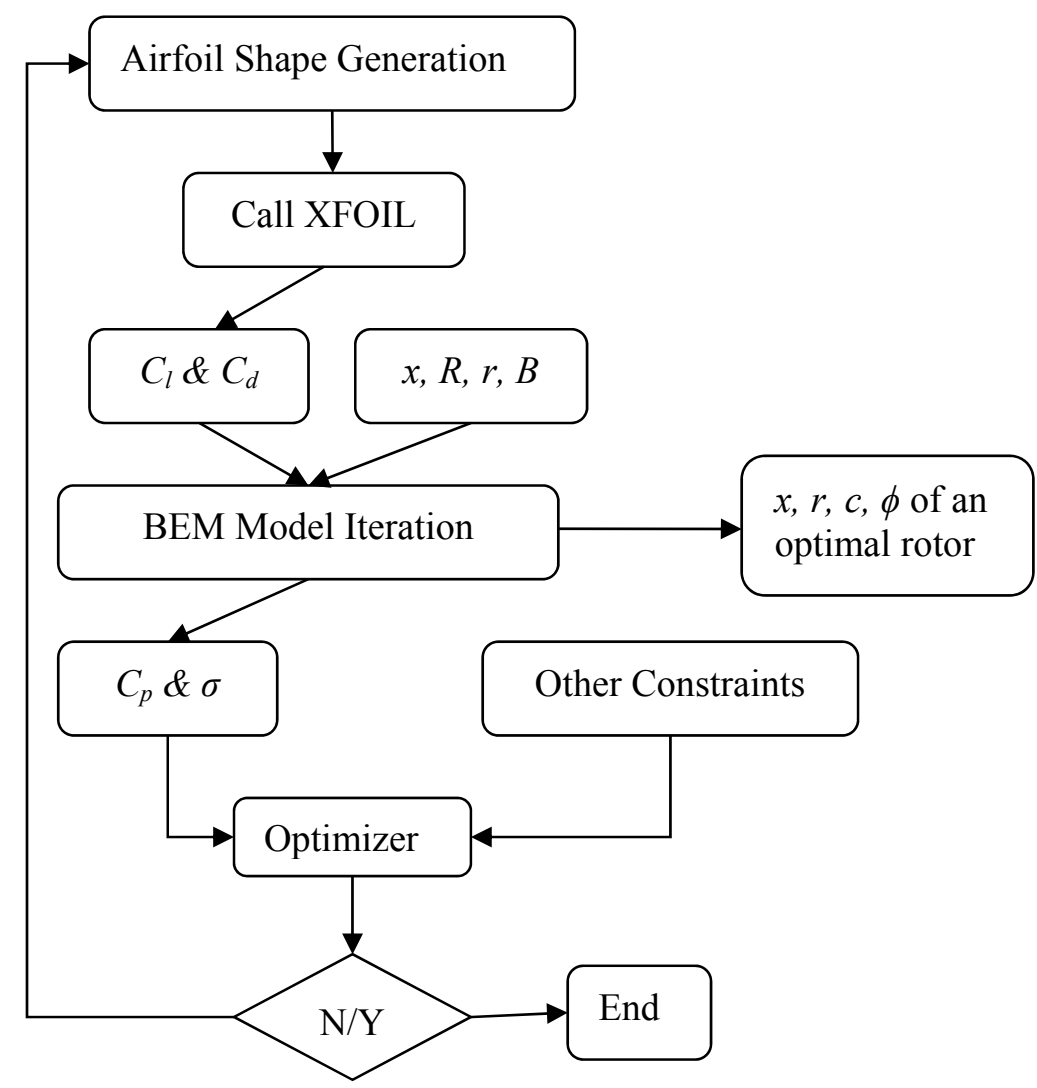

Figure 1. Flow chart of the integrated design.

The integrated design process is summarized in Figure 1. As seen in the flow chart, the main loop goes through the airfoil shape optimization and the 2D-BEM iteration is inside the main loop. The 2D-BEM calculation is an important part of the integrated design concept which links the airfoil optimization with the optimal blade design. The BEM iteration requires input from airfoil aerodynamics and blade local speed ratio etc. When the BEM converges, it forms an output to both the airfoil optimizer and the optimal rotor design. The final optimal rotor is found when the airfoil optimizer finds a converged solution.

\section{Airfoil design and analysis}

Before starting the design work, two key parameters are pre-defined for the blade: the rotor size and the TSR. As mentioned earlier the design TSR is 8 and the blade length is $130 \mathrm{~m}$. This is considered as an upscaling case of the $5 \mathrm{MW}$ virtual wind turbine [9]. The local speed ratios, the local blade radius and the number of blades are the basic inputs to start the integrated design.

\subsection{Design conditions}

The design Reynolds number is estimated to be about $\mathrm{Re}=16 \times 10^{6}$ depending on the radial location. The Mach number at the blade tip is set to $M_{\infty}=0.25$. The Mach number changes according to the local speed ratio. Design angle of attack is between $3^{\circ}$ and $10^{\circ}$. Numerical computations go through each angle of attack between $3^{\circ}$ and $10^{\circ}$. The wide range of angle of attack takes into account the off-design condition. Free transition simulation is based on the $e^{n}$ model with $n=9$; forced transition simulation is carried out by fixing the upper and lower transition points at 5\% and $10 \%$ chords measured from the leading edge, respectively. The numerical tool used for airfoil design is the Xfoil code developed by Drela [10]. The Xfoil code is iteratively used inside the optimization loop. All the above mentioned flow conditions are written as an input script that is recognized by Xfoil code.

\subsection{Design variables}

The choice of design variables is directly related to airfoil shape parameterization. Although lots of functions can be used to describe airfoil shapes, however, it is imperative to choose proper functions to represent airfoil geometry. In the 
present study, instead of creating a new airfoil shape, a shape perturbation function is applied to modify an existing airfoil. The idea of using such function is to save computational time and inherit the shape from previous airfoils. The sum of the shape perturbation function used for the upper surface is

$$
\Delta y_{u}(i)=\sum_{k=1}^{N} f_{u}(k) P_{u}(k, i)
$$

and similar for the lower surface,

$$
\Delta y_{l}(i)=\sum_{k=1}^{N} f_{l}(k) P_{l}(k, i)
$$

In Eq. (8) and (9) the lower subscripts $u$, and $l$ stand for the lower and upper airfoil surfaces, respectively, $i$ is the index of the $x$ and $y$ coordinates, $k$ is the index of the shape modes. The shape functions for each mode along the $x$-coordinate are

$$
\begin{gathered}
P_{u}(k, i)=\sin ^{\xi}\left(\pi x_{u}(i)^{g(k)}\right) \\
P_{l}(k, i)=\sin ^{\eta}\left(\pi x_{l}(i)^{g(k)}\right) .
\end{gathered}
$$

The amplitudes $f_{u}$ and $f_{l}$ in Eq. (8) and (9) are the design variables, and plus two more power factors of $\xi$, $\eta$, this gives a total number of design points $d o f s=2 * N+2$. $g$ is a given vector which is the exponent of $x$. For example, the choice of $g$

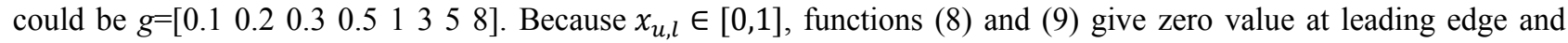
trailing edge points. Therefore leading edge and trailing edges are naturally fixed without being perturbed.

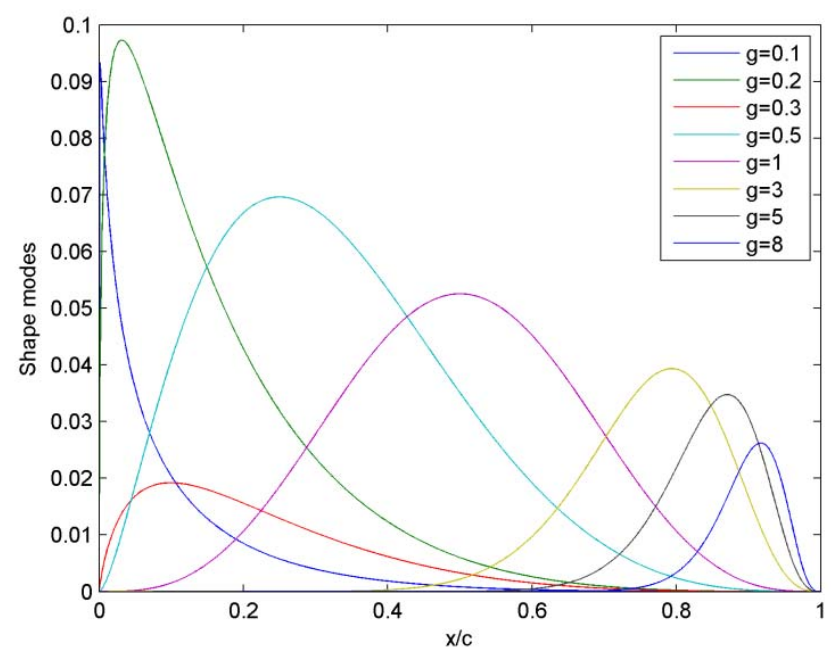

Figure 2. Example of the shape function.

Figure 2 shows an example of the shape perturbation function. The sum of the mode shapes will be added to the reference airfoil. One can add more shape modes to put more focus at any chord-wise location. For example, adding more values of $g<0.1$ leads to more detailed changes at leading edge. The amplitude coefficients $f_{u}$ and $f_{l}$ are updated after each iteration until the final airfoil shape is found.

\subsection{Design objective}

The design objective is the blending of power coefficient and the rotor solidity, such that

$$
O b j=k C_{p}+(1-k) \sigma^{-1}
$$

where $k=0.5$ for the middle part of the blade. The $k$ value shall be modified along the blade station while the solidity changes.

To obtain good off-design property, the power coefficient is weighted between clean and rough conditions with the angle of attack ranging from $\alpha=3^{\circ}$ to $\alpha=10^{\circ}$. 


$$
C_{p}=0.25 \sum_{\alpha=3}^{10} C_{p}^{\text {clean }}+0.75 \sum_{\alpha=3}^{10} C_{p}^{\text {rough }}
$$

If the converged solution can be found by the optimizer, Eq. (13) indicates that the resulted power coefficient will be insensitive to surface roughness and will keep high value over wide range of AOA.

\subsection{Design constrains}

The design constrains are: 1 . thickness to chord ratio; 2. limited maximum lift; 3 . limited difference in maximum lift for clean and rough cases to ensure less roughness sensitivity; 4. maximum thickness location $x_{\max } / c$, for shape compatibility consideration; 5 . Thickness constrain near the trailing edge, for structure consideration; 6 . smooth surface curvature for surface structure consideration. The tolerance used for these constrains is between $10^{-4}$ and $10^{-3}$ depending on the type of constrains.

\subsection{Optimization results}

Since the new airfoils are optimized using our baseline DTU-LN2-xx airfoil family, for the purpose of this paper the resulting airfoil will be referred to as DTU-R130-xx airfoils. The designed airfoil family has five airfoils of thickness to chord ratio ranging from $18 \%$ to $30 \%$. These geometries are plotted in Figure 3 . To ensure less three dimensional effects due to curvature change along the blade span, the airfoils are designed to have smooth geometrical transition between each other. The shape compatibility is well controlled by the design constrains.

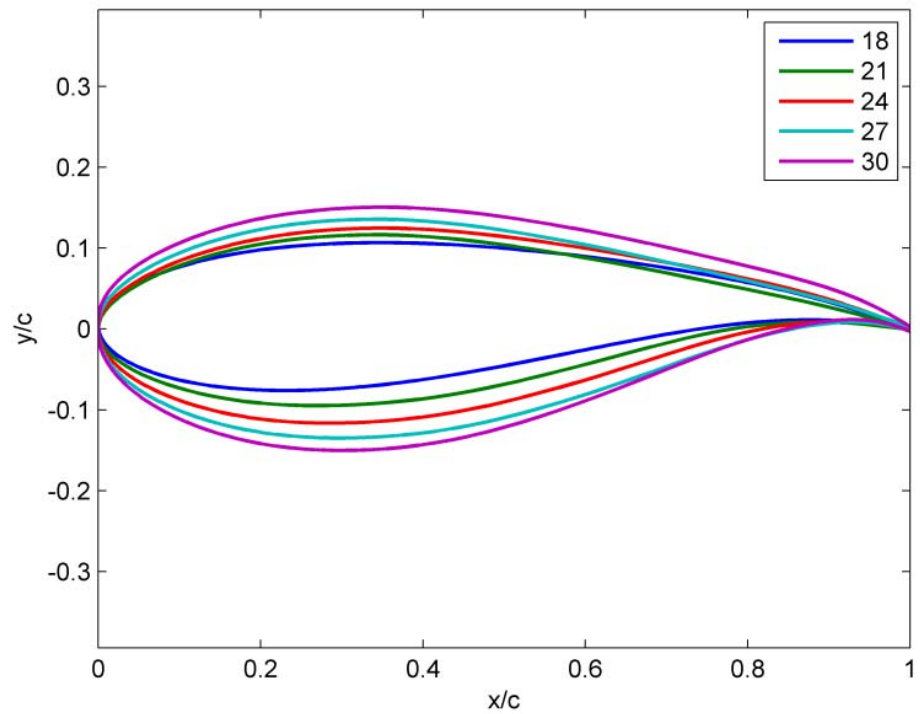

Figure 3. Airfoil shapes.

Some key design values are given in Table 1 . The outer part (110-130m) of the blade is constructed with R130-18. The middle part (40-80m) contains R130-21, R130-24, R130-27 and R130-30. The inner part (0-40m) is interpolated between cylinder and R130-30. The corresponding local speed ratios are calculated in the table which are inputs to the optimization model. For sake of manufacturing, the resulting airfoils have increased trailing edge thickness along the blade. Considering the blade shape compatibility, the maximum thickness location also increases while thickness increases, it is referred to as $x_{\max } / c$, the values are seen in the table as well. The design lift and maximum lift for the clean and rough cases are calculated for all the airfoils. According to the design constrains, the difference in $\mathrm{C}_{l}$ between clean and rough cases has to be small. For example of the R130-18 airfoil, the design lift coefficients $C_{L d e}$ are 1.24 and 1.21 for clean and rough conditions, respectively. In general, all the designed airfoils have good characteristics of roughness insensitivity.

\begin{tabular}{|l|l|l|l|l|l|l|l|l|l|l|}
\hline Thickness & 18 & 18 & 18 & 21 & 24 & 27 & 30 & 50 & 100 \\
\hline \multicolumn{8}{|c|}{ Step1: Pre-define blade length and TSR } \\
\hline $\mathrm{r}(\mathrm{m})$ & 130 & 125 & 110 & 80 & 65 & 50 & 40 & 30 & 0 \\
\hline$\lambda$ & 8 & 7.69 & 6.77 & 4.92 & 4 & 3.08 & 2.46 & 1.54 & - \\
\hline \multicolumn{8}{|c|}{ Step 2: Airfoil design based on the local TSR } \\
\hline
\end{tabular}




\begin{tabular}{|l|l|l|l|l|l|l|l|l|l|}
\hline Bluntness & - & - & 0.2 & 0.23 & 0.3 & 0.5 & 0.6 & - & - \\
\hline $\mathrm{x}_{\max } / \mathrm{c}$ & - & 0.278 & 0.278 & 0.308 & 0.314 & 0.314 & 0.327 & - & 100 \\
\hline $\mathrm{C}_{\mathrm{Lde}}$ & - & - & $1.24 / 1.21$ & $1.25 / 1.21$ & $1.4 / 1.34$ & $1.39 / 1.29$ & $1.41 / 1.24$ & - & - \\
\hline $\mathrm{C}_{\mathrm{Lmax}}$ & - & - & $2.04 / 2.03$ & $1.97 / 1.96$ & $1.97 / 1.95$ & $1.89 / 1.86$ & $1.89 / 1.85$ & - & - \\
\hline$\left(\mathrm{C}_{\mathrm{L}} / \mathrm{C}_{\mathrm{D}}\right)_{\max }$ & - & - & $146 / 137$ & $160 / 130$ & $150 / 119$ & $151 / 108$ & $132 / 84$ & - & - \\
\hline \multicolumn{8}{|c|}{ Step3: Blade construction based on the optimal airfoils } \\
\hline Chord $(\mathrm{m})$ & 0 & 2.4 & 3.57 & 4.91 & 5.37 & 6.99 & 8.67 & 10 & 7 \\
\hline$\beta\left(^{\circ}\right)$ & - & 0.62 & 0.68 & 1.65 & 2.34 & 4.96 & 7.7 & 11 & - \\
\hline$\phi\left({ }^{\circ}\right)$ & - & 5.62 & 5.68 & 7.65 & 9.34 & 11.96 & 14.7 & 18 & - \\
\hline Solidity & - & 0.009 & 0.015 & 0.029 & 0.039 & 0.668 & 0.10 & - & - \\
\hline $\operatorname{Re}\left(\times 10^{6}\right)$ & - & 12.4 & 16.3 & 16.4 & 14.8 & 15.1 & 15.4 & 10 & 5 \\
\hline
\end{tabular}

Table 1. Airfoil characteristics and blade parameters.

Figure 4 gives a closer look at the lift and drag characteristics of the R130-airfoils. A curve that weights between clean and rough flow conditions is shown in each sub-figure (solid line with triangles). The weighting coefficient is the same as used in Eq. (13). By looking at the horizontal axis, it is seen that the difference between maximum lift of clean and rough cases are small. The R130-18 and R130-21 airfoils have similar maximum lift and the other airfoils have less maximum lift due to increased thickness. The maximum lift has been limited at a certain level to keep maximum thrust under a certain level. By looking at the vertical axis, it is observed that the lift to drag ratio is kept at high level over wide range of lift which implies good off-design property. It is interesting to check the local power coefficients since it is an index that measures the quality of the optimization. The $C_{p}$ values at different angles of attack are shown in Figure 5. It is found by numerical simulation that the $C_{p}$ values are relatively high for all the airfoils. And more importantly the $C_{p}$ curves are quite flat, i.e. between 5 to 9 degrees. These are the aerodynamic properties expected as the design objective.

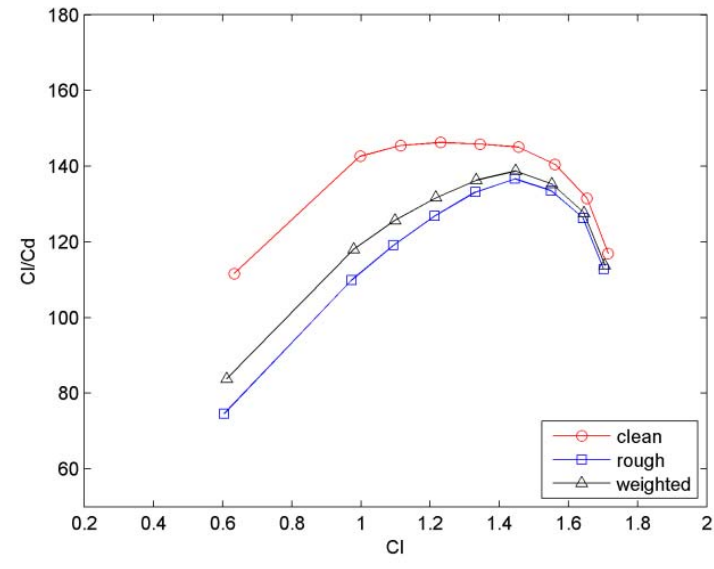

(a)

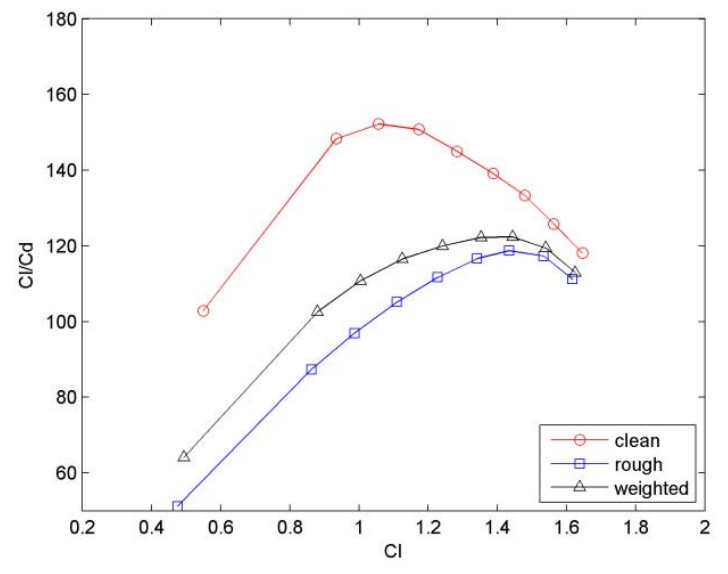

(c)

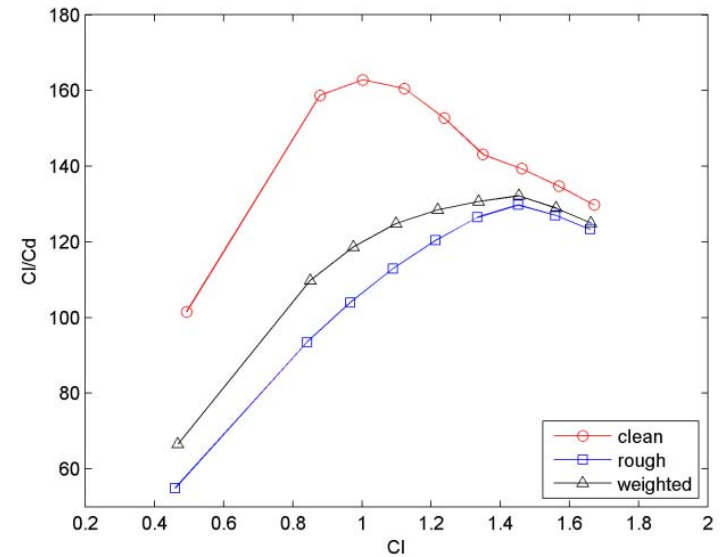

(b)

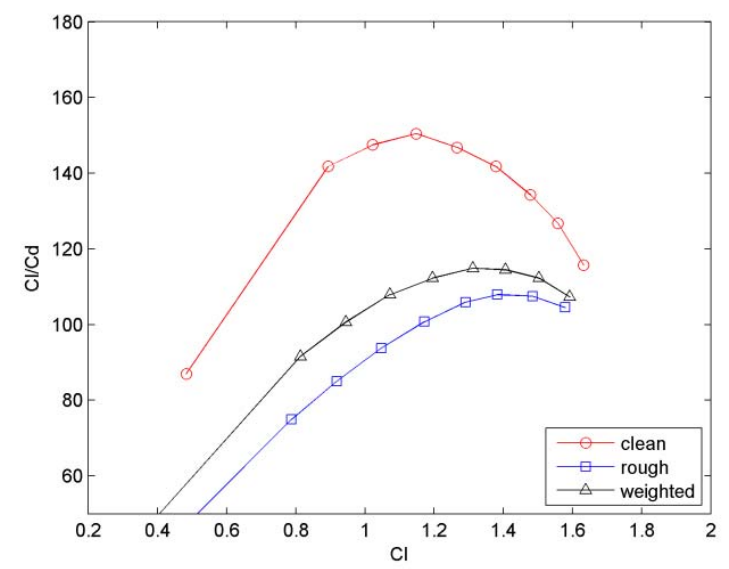

(d) 


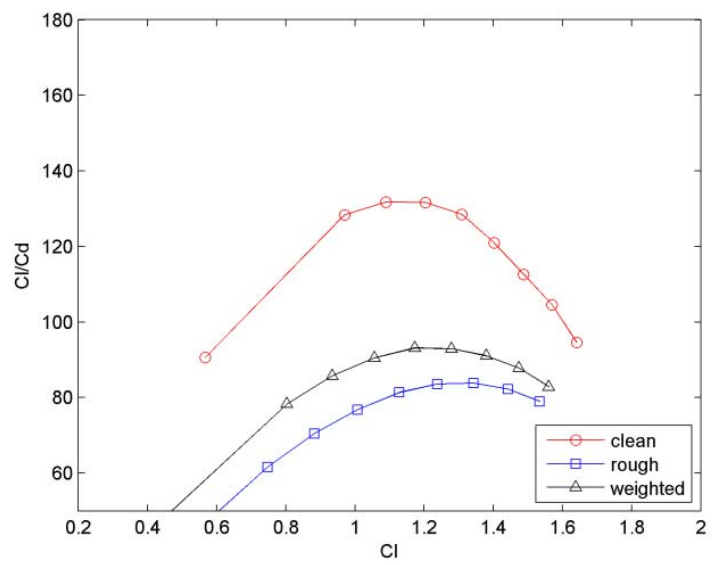

(e)

Figure 4. Lift against lift to drag ratios. (a) R130-18; (b) R130-21; (c) R130-24; (d) R130-27; (e) R130-30.

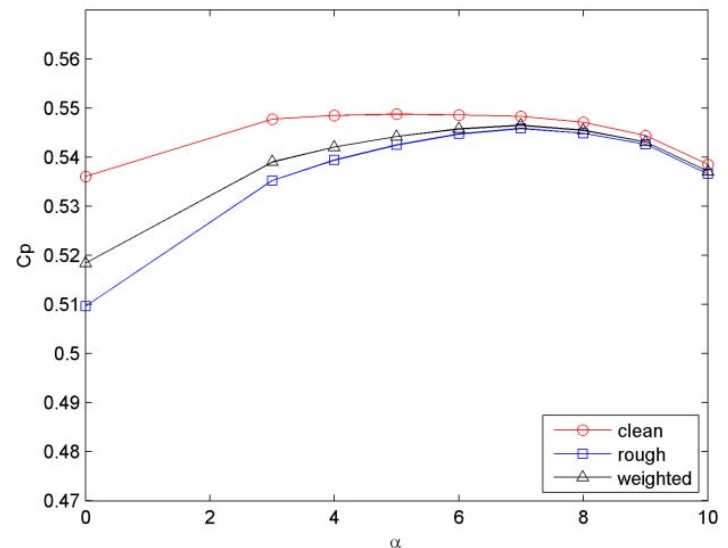

(a)

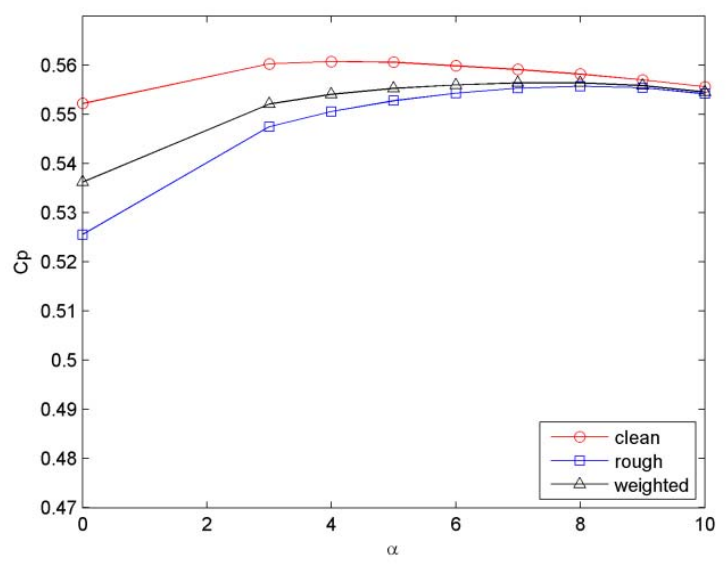

(c)

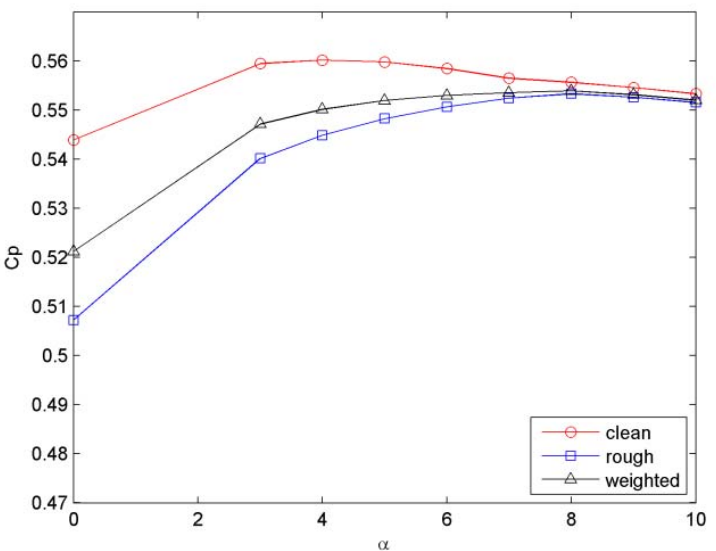

(b)

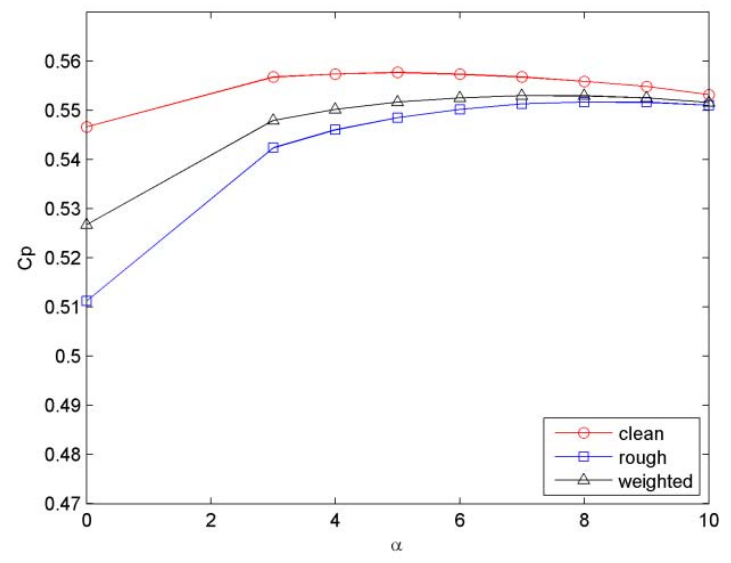

(d) 


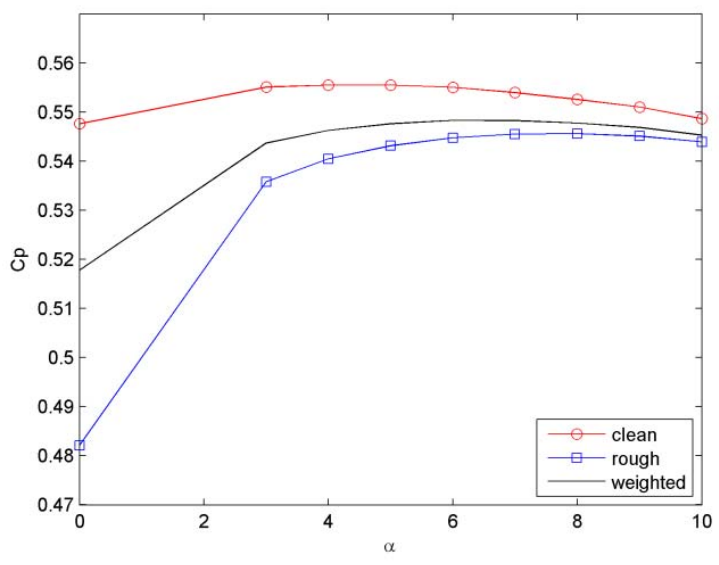

(e)

Figure 5. $C_{p}$ at different AOA. (a) R130-18; (b) R130-21; (c) R130-24; (d) R130-27; (e) R130-30.

\section{The platform of the optimal rotor}

For each airfoil shown in Figure 1, according to Eq. (12), a local high $C_{p}$ value can be obtained at a given blade radial position and it is the same for the local solidity. When such objective is achieved after some steps of airfoil optimization, the optimum values of chord length and flow angle are obtained. The chord and twist distributions form the basic platform of the optimum rotor, such distributions are shown in Figure 6 and Figure 7. These numbers are also seen in Table 1. Until now the whole process of the integrated design has been shown with a result of high $C_{p}$ value and small solidity. However, these results are based on the assumption of an idealized normal induction factor $1 / 3$. Further blade optimization shall be carried out based on the present baseline platform. The more detailed blade optimization must include the sophisticated BEM model which also calculates the induction factors. Beside this, the measured airfoil data are required as input to the BEM code.

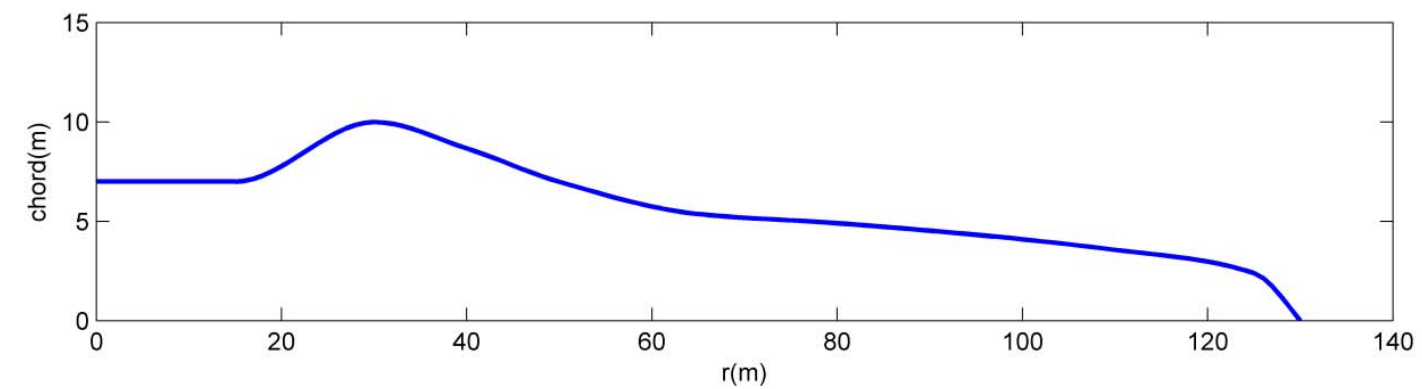

Figure 6. Chord distribution of the pre-designed blade. Platform envelop based on the designed airfoils.

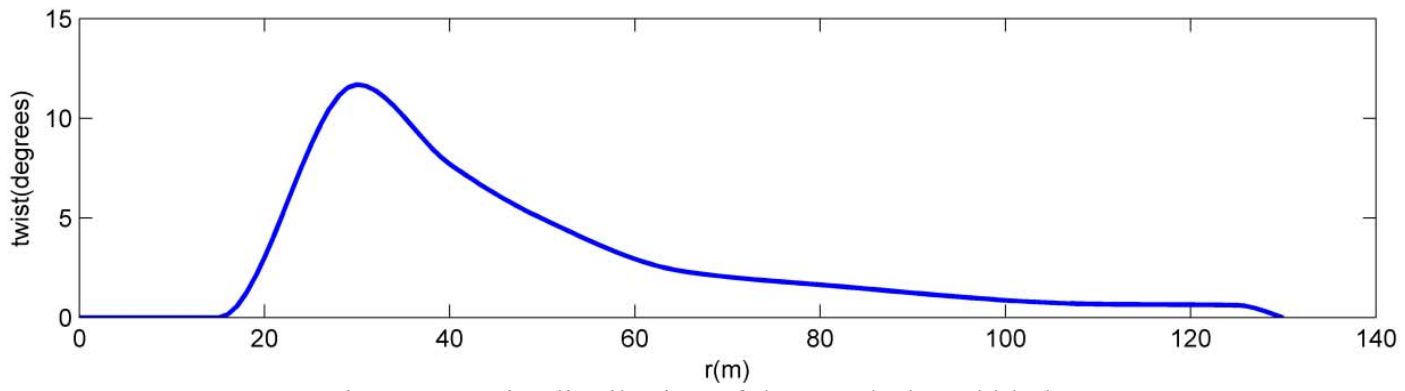

Figure 7. Twist distribution of the pre-designed blade. 


\section{Conclusions}

An integrated method to design airfoils and rotor blade is introduced. The design procedure mainly includes three steps. The first step is to pre-define the TSR and the rotor size. These two parameters determine the output airfoils and the blade platform. Step two is the airfoil optimization based on the blade local speed ratio. 2D airfoil BEM computation is involved during airfoil optimization which provides values of local power coefficient and rotor solidity for the airfoil optimizer. In step three, results from BEM are collected at the final iteration of the airfoil optimization loop. Such results represent the condition of the optimal flow angle and chord length exists. Most of the computational effort has been put in step two where airfoils are optimized. The common characteristics of the resulted airfoils are high $C_{p}$ over wide range of angle of attack. The airfoils are also very insensitive to roughness condition. As a result of the BEM computation, the optimal platform for the blade is obtained which can be regarded as the baseline shape for further optimization.

\section{Acknowledgement}

The research work is partially supported by two projects. The authors wish to express acknowledgement to the Danish Energy Agency (EUDP project j.nr. 64011-0094) and the Ministry of Science (DSF project Sagsnr. 12-130590).

\section{References}

[1] Hicks RM., Murman EM, and Vanderplaats GN. An assessment of airfoil design by numerical optimization. NASA TM X-3092, July 1974.

[2] Tangler JL, Somers DM. Status of the special purpose airfoil families. Proc. WINDPOWER'87, San Francisco, 1987.

[3] Tangle JL, Somers D M. NREL airfoil families for HAWT's. WINDPOWER'95, Washington D.C. Proc., 1995, $117-123$.

[4] Fuglsang P, Bak C. Development of the RIS $\varnothing$ wind turbine airfoils [J]. Wind Energy 2004; 7:145-162.

[5] Wang XD, Chen J, Shen WZ, Zhu WJ and Sørensen JN. Airfoils and methods for designing airfoils [P]. Application No. PCT/EP2010/056810, International patent application.

[6] Wang XD, Chen J, Shen WZ, Zhang S. Integration study on airfoil profile for wind turbines. Journal of China Mechanical Engineering. 2009, 20(2): 211-228.

[7] Bak C. Research in aeroelasticity EFP-2006: Key parameters in aerodynamic rotor design. RIS $\varnothing$ National laboratory, Roskilde, Denmark.2007. RISØ-R-1611(EN).

[8] Shen WZ, Mikkelsen R and Sørensen JN. Tip Loss Corrections for Wind Turbine Computations. Wind Energy Wiley, 2005.

[9] Jonkman J, Butterfield S, Musial W and Scott G. Definition of a 5-MW reference wind turbine for offshore system development, Technical Report NREL/TP-500-38060, Golden, CO: National Renewable Energy Laboratory, February 2009.

[10] Drela M, XFOIL: An analysis and design system for low Reynolds number airfoils, Conference on Low Reynolds Number Aerodynamics, University of Notre Dame, 1989. 